\title{
Effectiveness of influenza vaccine in preventing medically-attended influenza virus infection in primary care, Israel, influenza seasons 2014/15 and 2015/16
}

Hamutal Yaron-Yakoby ${ }^{1}$, Hanna Sefty ${ }^{2}$, Rakefet Pando ${ }^{2,3}$, Rita Dichtiar ${ }^{2}$, Mark A Katz ${ }^{4,5}$, Yaniv Stein ${ }^{2}$, Michal Mandelboim ${ }^{1,3}$, Ella Mendelson ${ }^{1,3}$, Tamy Shohat ${ }^{1,2}$, Aharona Glatman-Freedman ${ }^{1,2,6}$, the Israeli Influenza Surveillance Network (IISN) ${ }^{7}$

1. Department of Epidemiology and Preventive Medicine, School of Public Health, Sackler Faculty of Medicine Tel Aviv University, Tel Aviv, Israel

2. Israel Center for Disease Control, Israel Ministry of Health, Tel Hashomer, Ramat Gan, Israel

3. Central Virology Laboratory, Israel Ministry of Health, Chaim Sheba Medical Center, Ramat Gan, Israel

4. Ben Gurion University, Beer Sheva, Israel

5. School of Public Health, University of Michigan, Ann Arbor, Michigan, United States

6. Departments of Pediatrics and Family and Community Medicine, New York Medical College, Valhalla, New York, United States

7. The members of the group are listed at the end of the paper

Correspondence: Aharona Glatman-Freedman (aharona.freedman@moh.health.gov.il)

Citation style for this article:

Yaron-Yakoby Hamutal, Sefty Hanna, Pando Rakefet, Dichtiar Rita, Katz Mark A, Stein Yaniv, Mandelboim Michal, Mendelson Ella, Shohat Tamy, Glatman-Freedman Aharona, the Israeli Influenza Surveillance Network (IISN). Effectiveness of influenza vaccine in preventing medically-attended influenza virus infection in primary care, Israel, influenza seasons 2014/15 and 2015/16. Euro Surveill. 2018;23(7):pii=17-00026. https://doi.org/10.2807/1560-7917.ES.2018.23.7.17-00026

Introduction: Influenza vaccine is recommended for the entire population in Israel. We assessed influenza vaccine effectiveness (VE) for the 2014/15 and 2015/16 seasons in Israel, for the first time. Methods: Combined nose and throat swab specimens were collected from patients with influenza-like illness (ILI) presenting to sentinel primary care clinics and tested for influenza virus by RT-PCR. VE of the trivalent inactivated vaccine (TIV) was assessed using test-negative case-control design. Results: During the $2014 / 15$ season 1,142 samples were collected; $327(28.6 \%)$ were positive for influenza, $83.8 \% A\left(\mathrm{H}_{3} \mathrm{~N}_{2}\right), 5.8 \% A\left(\mathrm{H}_{1} \mathrm{~N}_{1}\right)$ pdmo9, 9.2\% $B$ and $1.2 \%$ A un-subtyped. Adjusted VE against all influenza viruses for this influenza season was $-4.8 \%$ ( $95 \%$ confidence interval $(\mathrm{Cl}):-54.8$ to 29.0 ) and against influenza $\mathrm{A}\left(\mathrm{H}_{3} \mathrm{~N}_{2}\right)$, it was $-15.8 \%(95 \%$ $\mathrm{Cl}:-72.8$ to 22.4 ). For the $2015 / 16$ season, 1,919 samples were collected; 853 (44.4\%) were positive for influenza, 43.5\% $A\left(\mathrm{H}_{1} \mathrm{~N}_{1}\right)$ pdmo9, $57 \% \mathrm{~B}, 0.7 \% \mathrm{~A}\left(\mathrm{H}_{3} \mathrm{~N}_{2}\right)$ and 11 samples positive for both $A\left(\mathrm{H}_{1} \mathrm{~N}_{1}\right)$ pdmog and $B$. Adjusted VE against all influenza viruses for this influenza season was $8.8 \%$ ( $95 \% \mathrm{Cl}:-25.1$ to 33.5 ), against influenza $A\left(\mathrm{H}_{1} \mathrm{~N}_{1}\right)$ pdmo9, it was $32.3 \%(95 \% \mathrm{Cl}:(-4.3$ to 56.1$)$ and against influenza $B$, it was $-2.2 \%(95 \%$ $\mathrm{Cl}$ : (-47.0 to 29.0). Conclusions: Using samples from patients with ILI visiting sentinel clinics in Israel, we demonstrated the feasibility of influenza VE estimation in Israel.

\section{Introduction}

Influenza virus infection causes morbidity and mortality worldwide every year [1]. The most effective measure of preventing influenza is the influenza vaccine.
However, influenza vaccine effectiveness (VE) can vary considerably, both by season [2], and geographic location $[2,3]$.

Israel is a country of 8.5 million people, with a Mediterranean and arid climate, located in the westernmost part of Asia. In Israel, influenza activity is seasonal, usually occurring from December through March [4] in patterns similar to those of Europe and those in neighbouring Jordan [5] and Egypt [6]. The outpatient sentinel influenza surveillance system was established in the 1996/97 season and has been conducted through primary care clinics throughout Israel. The sentinel clinics are located in all seven districts of Israel and are staffed by paediatricians, internists and family physicians. During the 2014/15 and 2015/16 influenza seasons, 23 and 26 sentinel clinics, respectively, participated in influenza surveillance. Israel's Ministry of Health recommends influenza vaccination for the entire population over the age of 6 months [7]. The trivalent inactivated vaccine (TIV), the quadrivalent inactivated vaccine (QIV) and live attenuated influenza vaccine (LAIV) are all registered for use in Israel. The inactivated vaccines against seasonal influenza are offered free of charge to all residents through clinics of the four national 'sick fund' organisations which are widely spread throughout the country and are similar to health maintenance organisations in the United States (US). TIV is the most widely used influenza vaccine in Israel.

In this study we evaluated, for the first time, VE against medically attended laboratory-confirmed influenza-like 
Weekly distribution of influenza-positive samples from outpatient sentinel clinics, Israel, influenza seasons 2014/15 and 2015/16

\section{A. 2014/15 influenza season}

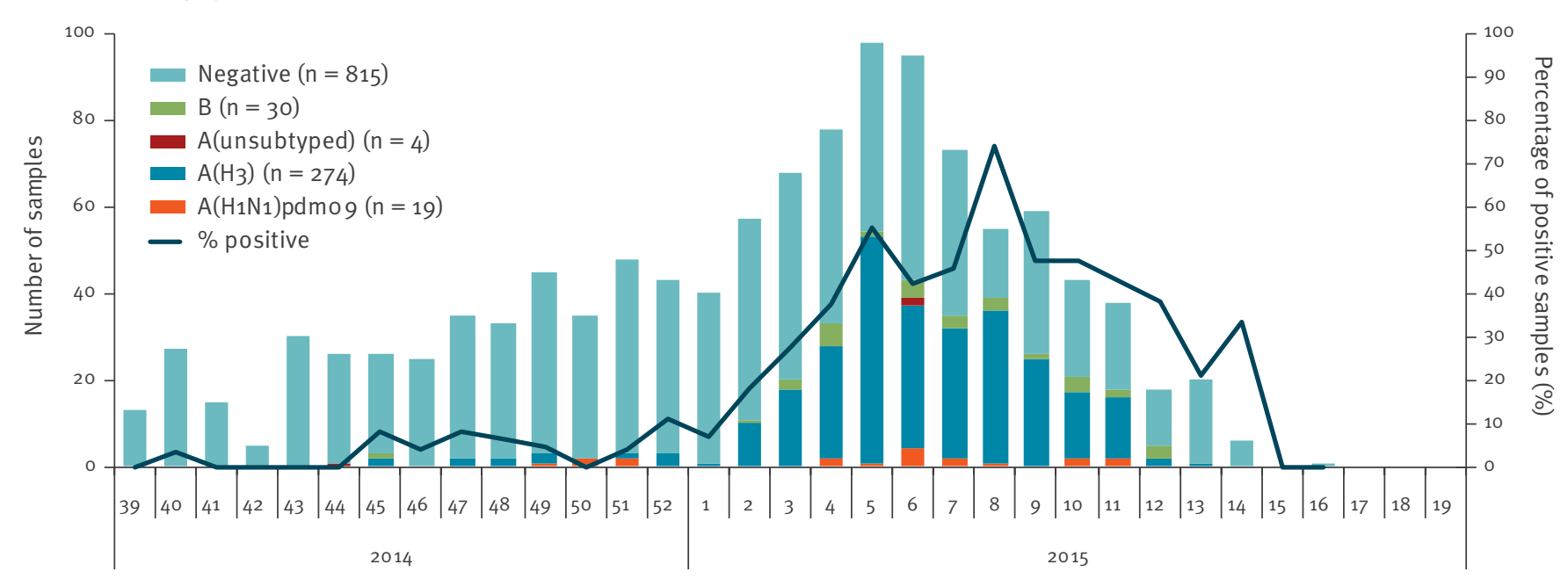

Week and year

\section{B. 2015/16 influenza season}

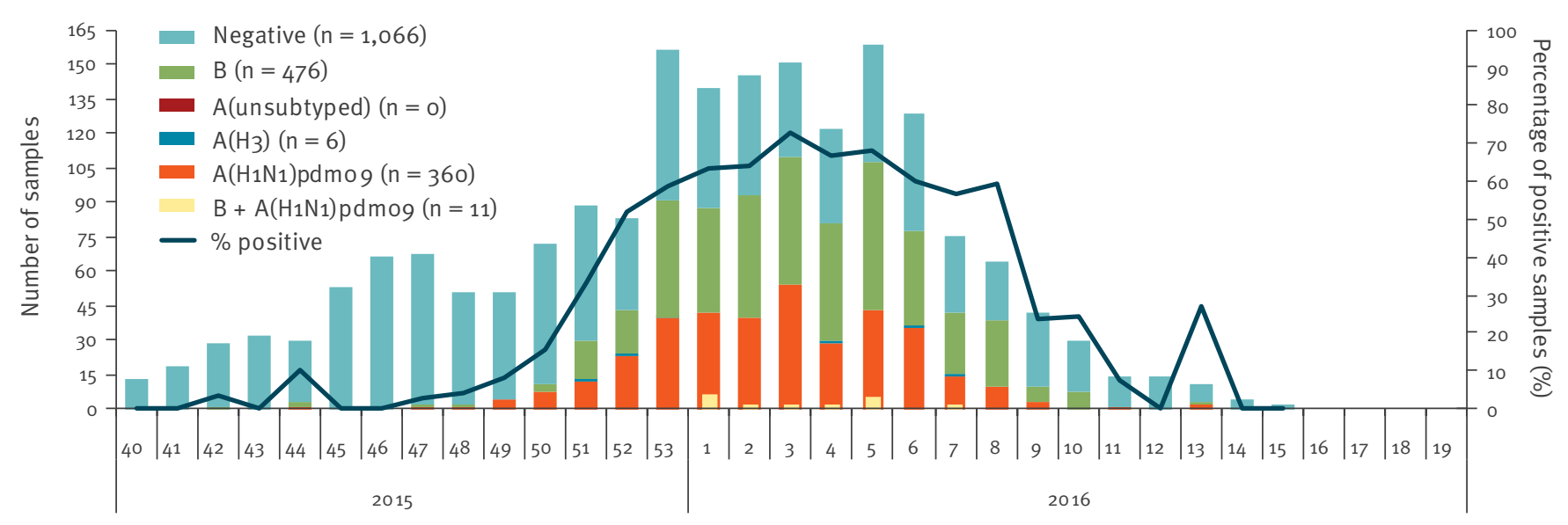

Week and year

illness (ILI) in the community in Israel using our sentinel surveillance system. The predominant influenza strain in the 2014/15 season was a drifted influenza $A\left(\mathrm{H}_{3} \mathrm{~N}_{2}\right)$. Influenza $A\left(\mathrm{H}_{1} \mathrm{~N}_{1}\right)$ pdm2009 and influenza $B$ co-circulated in Israel during the $2015 / 16$ season. The overall influenza vaccination coverage in Israel during the $2014 / 15$ and $2015 / 16$ seasons was ca $21 \%$. The vaccine coverage was ca $65 \%, 25 \%$ and $40 \%$ among individuals age 65 years of age and over, infants and children 6 months to 5 years, and individuals less than 65 years of age with chronic medical conditions, respectively $[8,9]$.

We used the test-negative case-control design, a commonly used method for estimating influenza VE in studies that utilise sentinel surveillance systems [10].

\section{Methods}

\section{Study period and population}

Influenza surveillance periods lasted in Israel from 28 September 2014 until 18 April 2015, and from 27 September 2015 until 16 April 2016. During these periods, sentinel clinic providers obtained combined nasal and throat swabs [11] from a convenience sample of patients meeting the ILI case definition. The kits of combined nasal and throat swabs were provided to all sentinel clinics by the Israel Center for Disease Control. ILI was defined as a temperature of $37.8^{\circ} \mathrm{C}$ and over, accompanied by one or more of the following symptoms: coryza, sore throat, cough, and muscle ache [12]. Discretion was given to physicians to include other signs or symptoms considered relevant. Sentinel clinics were asked to send up to ten samples per week. 


\section{FIGURE 2}

Flowchart of influenza-like illness patients from sentinel primary care clinics, Israel, influenza seasons 2014/15 and 2015/16 $(\mathrm{n}=1,142$ and 1,919 , respectively)

\section{A. 2014/15 influenza season}

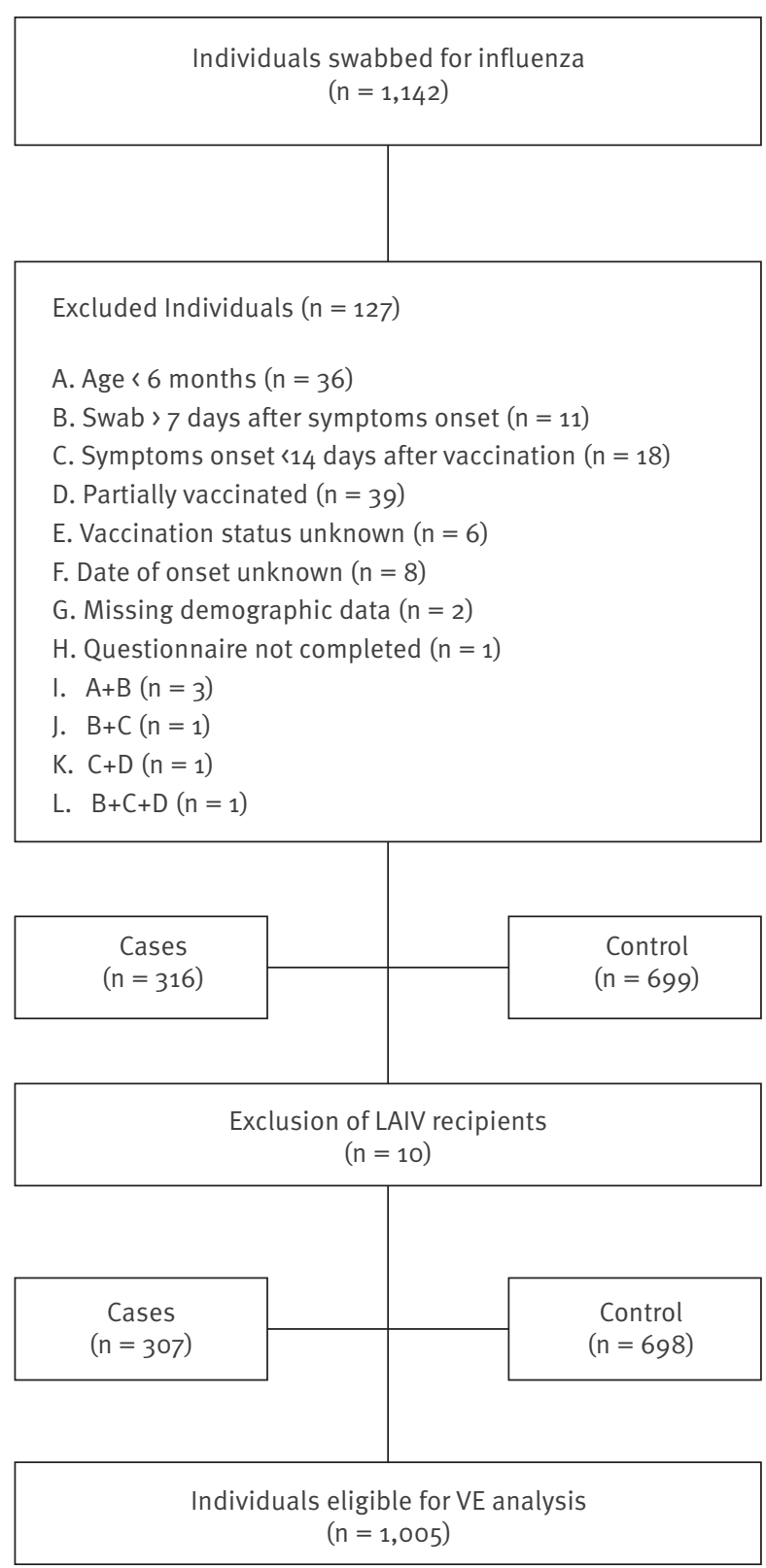

B. $2015 / 16$ influenza season

Individuals swabbed for influenza

$(n=1,919)$

Excluded Individuals $(\mathrm{n}=249)$
A. Age $<6$ months $(n=41)$
B. Swab $>7$ days after symptoms onset $(n=60)$
C. Symptoms onset $<14$ days after vaccination $(n=50)$
D. Partially vaccinated $(n=36)$
E. Vaccination status unknown $(n=8)$
F. Type of vaccine unknown $(n=20)$
G. Date of onset unknown $(n=25)$
H. Missing sample date $(n=2)$
I. Laboratory results unavailable $(n=1)$
J. $A+B(n=4)$
K. $B+C(n=1)$
L. $\mathrm{E}+\mathrm{H}(\mathrm{n}=1)$

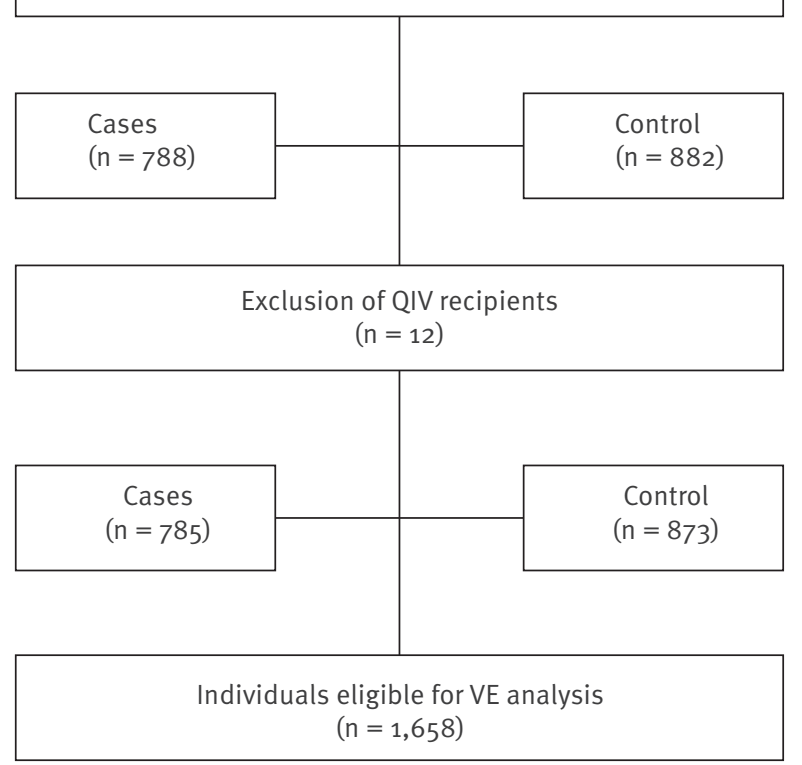

LAIV: live attenuated influenza vaccine; QIV: quadrivalent inactivated influenza vaccine; VE: vaccine effectiveness.

For each patient a questionnaire with demographic, epidemiologic and clinical data was completed by sentinel medical staff. The data included date of birth, sex, date of disease onset, date of sample collection and influenza vaccine status for the evaluated season, including the date of vaccination and the type of vaccine used. For children less than 9 years of age, providers recorded whether a second dose was needed (for those receiving the influenza vaccine for the first time) and the date of the second dose, if indicated.
Information regarding chronic medical conditions placing patients at risk for influenza-related complications was available for the $2015 / 16$ season.

\section{Molecular identification of influenza viruses in samples obtained from sentinel patients with influenza-like illness}

The combined nasal and throat samples from sentinel ILI patients were kept at ${ }^{\circ} \mathrm{C}$ in the upright position until transport. Samples were transported once a week 
Characteristics of samples from influenza-like illness patients eligible for vaccine effectiveness analysis, Israel, influenza season 2014/15 ( $\mathrm{n}=1,005)$

\begin{tabular}{|c|c|c|c|c|c|c|c|c|}
\hline \multirow{3}{*}{ Characteristics } & \multirow[b]{2}{*}{$\begin{array}{l}\text { Controls } \\
(n=698)\end{array}$} & \multicolumn{5}{|c|}{ Influenza types and subtypes of cases $(n=307)$} & \multirow[b]{2}{*}{$\begin{array}{c}\text { Total } \\
(\mathrm{n}=1,005)\end{array}$} & \multirow{3}{*}{$\mathrm{p}$ value } \\
\hline & & $\begin{array}{c}\text { Total A } \\
(n=277)\end{array}$ & $\begin{array}{c}\mathrm{A}\left(\mathrm{H}_{1} \mathrm{~N}_{1}\right) \mathrm{pdm} \\
(\mathrm{n}=17)\end{array}$ & $\begin{array}{l}\mathrm{A}\left(\mathrm{H}_{3} \mathrm{~N}_{2}\right) \\
(\mathrm{n}=257)\end{array}$ & $\begin{array}{c}\text { A(unsubtyped) } \\
(\mathrm{n}=3)\end{array}$ & $B(n=30)$ & & \\
\hline & $\mathrm{n}(\%)^{\mathrm{a}}$ & $\mathrm{n}(\%)^{\mathrm{a}}$ & $\mathrm{n}(\%)^{\mathrm{a}}$ & $n(\%)^{a}$ & $n(\%)^{a}$ & $n(\%)^{a}$ & $n(\%)^{b}$ & \\
\hline \multicolumn{9}{|l|}{ Age groups } \\
\hline 6 months -17 years & $413(70.2)$ & $\begin{array}{c}165 \\
(28.1)\end{array}$ & $7(1.2)$ & $157(26.7)$ & $1(0.2)$ & $10(1.7)$ & $588(58.5)$ & \multirow{4}{*}{0.83} \\
\hline $18-44$ years & $193(68.0)$ & $\begin{array}{c}76 \\
(26.8) \\
\end{array}$ & $7(2.5)$ & 68 (23.9) & $1(0.4)$ & $15(5 \cdot 3)$ & $284(28.2)$ & \\
\hline $45-64$ years & $59(66.3)$ & $27(30.3)$ & $2(2.2)$ & $24(27.0)$ & $1(1.1)$ & $3(3.4)$ & $89(8.9)$ & \\
\hline$\geq 65$ years & $33(75.0)$ & $9(20.5)$ & $1(2.3)$ & $8(18.2)$ & $\mathrm{o}(0)$ & $2(4.5)$ & $44(4.4)$ & \\
\hline \multicolumn{9}{|l|}{ Sex } \\
\hline Male & $360(69.4)$ & $\begin{array}{c}142 \\
(27.3) \\
\end{array}$ & $8(1.5)$ & $133(25.6)$ & $1(0.2)$ & $17(3.3)$ & $519(51.6)$ & \multirow{2}{*}{0.95} \\
\hline Female & $338(69.6)$ & $\begin{array}{c}135 \\
(27.8)\end{array}$ & $9(1.8)$ & $124(25 \cdot 5)$ & $2(0.4)$ & $13(2.7)$ & $486(48.4)$ & \\
\hline \multicolumn{9}{|c|}{ Interval between symptom onset and swab } \\
\hline $0-1$ days & $365(71.0)$ & $\begin{array}{c}134 \\
(26.1) \\
\end{array}$ & $7(1.4)$ & $126(24.5)$ & $1(0.2)$ & $15(2.9)$ & $514(51.1)$ & \multirow{3}{*}{0.53} \\
\hline $2-4$ days & $299(67.0)$ & \begin{tabular}{|c|}
133 \\
$(29.8)$ \\
\end{tabular} & $9(2.0)$ & $122(27 \cdot 3)$ & $2(0.4)$ & $14(3.1)$ & $446(44.4)$ & \\
\hline 5-7 days & $34(75.6)$ & $10(22.2)$ & $1(2.2)$ & $9(20)$ & $\mathrm{o}(\mathrm{o})$ & $1(2.2)$ & $45(4.5)$ & \\
\hline \multicolumn{9}{|l|}{ Vaccination status $^{d}$} \\
\hline Unvaccinated & $577(69.9)$ & $\begin{array}{c}222 \\
(26.9) \\
\end{array}$ & $15(1.8)$ & $204(24.7)$ & $3(0.4)$ & $26(3.1)$ & $825(82.0)$ & \multirow{2}{*}{0.47} \\
\hline Vaccinated (TIV) & $121(67.2)$ & $\begin{array}{c}55 \\
(30.6)\end{array}$ & $2(1.1)$ & $53(29.4)$ & $\mathrm{o}(\mathrm{o})$ & $4(2.2)$ & $180(17.9)$ & \\
\hline
\end{tabular}

TIV: trivalent inactivated vaccine.

a Percentage based on total of each row.

${ }^{b}$ Percentage based on the total of 1,005.

' Analysis performed for influenza positive (cases) vs negative (controls).

${ }^{d}$ Individuals receiving live attenuated influenza vaccine (LAIV) $(n=10)$ were excluded from the table and analysis.

in cooling containers, by car, to the Central Virology Laboratory of the Israel Ministry of Health. The samples were tested for influenza by real-time RT-PCR. The viral genome was extracted from the samples during the 2014/15 season using NucliSENS easyMAG (BioMerieux, Marcy l'Etoile, France) and during the 2015/16 season using the KingFisher Purification System (Thermo Fisher Scientific, Vantaa, Finland) and the NucleoMag RNA (Macherey-Nagel, Düren, Germany) RNA extraction kit. Influenza viruses were then tested by real-time RT-PCR using Applied Biosystems 7500 Real-Time PCR system (Foster City, CA, US) and the Ambion Ag-Path Master Mix (Life Technologies, US) and TaqMan Chemistry (Foster City, CA, US) [13-16].

A subset of influenza $\mathrm{A}\left(\mathrm{H}_{3} \mathrm{~N}_{2}\right)$ circulating in Israel during the 2014/15 season, and subsets of influenza $\mathrm{A}\left(\mathrm{H}_{1} \mathrm{~N}_{1}\right)$ pdmog and $\mathrm{B}$ circulating in Israel during the $2015 / 16$ season underwent nt sequencing of the haemagglutinin (HA) gene. Sequenced viruses were from samples collected at various stages of each influenza season. Influenza HA gene-specific primers were used to partially amplify the influenza A and influenza B HA genes, as previously described according to World Health Organization (WHO) protocols [17].

Amplified PCR products were sequenced using $A B I$ PRISM Dye Deoxy Terminator cycle sequencing kit (Applied Biosystems, Foster City, CA, US). Reaction mixtures were then analysed using $A B I 3500$ DNA Genetic Analyzer (Applied Biosystems, Foster City, CA, USA). Alignment and comparison of nt sequences were carried out using the Sequencher software version 5.4 (Gencodes Corporation, Ann Arbor, MI, US). HA sequences of reference strains used for phylogenetic analysis were obtained from the EpiFlu database of the Global Initiative on Sharing All Influenza Data (platform.gisaid.org).

\section{Study design}

VE against influenza was assessed for individuals 6 months of age and over who received the TIV, using the test-negative case-control design $[18,19]$. VE was derived as (1-odds ratio $(O R)) \times 100$, expressed as a 
Characteristics of samples from influenza-like illness patients eligible for vaccine effectiveness analysis, Israel, influenza season $2015 / 16(n=1,658)$

\begin{tabular}{|c|c|c|c|c|c|c|c|c|}
\hline \multirow{3}{*}{ Characteristics } & \multirow{3}{*}{ 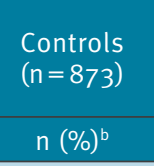 } & \multicolumn{5}{|c|}{ Influenza types and subtypes of cases $(n=785)$} & \multirow{3}{*}{$\begin{array}{c}\begin{array}{c}\text { Total } \\
(\mathrm{n}=1,658)\end{array} \\
\mathrm{n}(\%)^{\mathrm{c}}\end{array}$} & \multirow{3}{*}{$\begin{array}{c}\mathrm{p} \\
\text { value }^{\mathrm{d}}\end{array}$} \\
\hline & & \multirow{2}{*}{$\begin{array}{c}\begin{array}{c}\text { Total A } \\
(\mathrm{n}=348)^{\mathrm{a}}\end{array} \\
\mathrm{n}(\%)^{\mathrm{b}}\end{array}$} & \multirow{2}{*}{$\begin{array}{c}\begin{array}{c}\mathrm{A}\left(\mathrm{H}_{1} \mathrm{~N}_{1}\right) \mathrm{pdm} 09 \\
(\mathrm{n}=332)\end{array} \\
n(\%)^{\mathrm{b}}\end{array}$} & \multirow{2}{*}{$\begin{array}{c}\mathrm{A}\left(\mathrm{H}_{3} \mathrm{~N}_{2}\right) \\
(\mathrm{n}=5) \\
n(\%)^{\mathrm{b}}\end{array}$} & \multirow{2}{*}{$\begin{array}{c}\mathrm{A}\left(\mathrm{H}_{1} \mathrm{~N}_{1}\right) p \mathrm{pdmo}_{(\mathrm{n}} 0+\mathrm{B} \\
(\mathrm{n}=11) \\
\mathrm{n}(\%)^{\mathrm{b}}\end{array}$} & \multirow{2}{*}{$\begin{array}{c}B \\
(n=448)^{a} \\
n(\%)^{b}\end{array}$} & & \\
\hline & & & & & & & & \\
\hline \multicolumn{9}{|l|}{ Age groups } \\
\hline 6 months -17 years & $450(55.2)$ & $129(15.8)$ & $123(15.1)$ & o (o) & $6(0.7)$ & $242(29.7)$ & $815(49.2)$ & \multirow{4}{*}{0.83} \\
\hline $18-44$ years & $234(45.0)$ & $142(27.3)$ & $138(26.5)$ & $1(0.2)$ & $3(0.6)$ & $147(28.3)$ & $520(31.4)$ & \\
\hline $45-64$ years & $131(58.5)$ & $60(26.8)$ & $56(25.0)$ & $3(1.3)$ & $1(0.4)$ & $34(15.2)$ & $224(13.5)$ & \\
\hline$\geq 65$ years & $58(58.6)$ & $17(17.2)$ & $15(15.1)$ & $1(1.0)$ & $1(1.0)$ & $25(25.2)$ & $99(6.0)$ & \\
\hline \multicolumn{9}{|l|}{ Sex } \\
\hline Male & $434(52.8)$ & $178(21.6)$ & $169(20.6)$ & $3(0.4)$ & $6(0.7)$ & $216(26.3)$ & $822(49.6)$ & \multirow{2}{*}{0.91} \\
\hline Female & $439(52.5)$ & $170(20.3)$ & $163(19.5)$ & $2(0.2)$ & $5(0.6)$ & $232(27.8)$ & $836(50.4)$ & \\
\hline \multicolumn{9}{|c|}{ Chronic medical conditions } \\
\hline Yes & $172(60.6)$ & $49(17.2)$ & $45(15.8)$ & $2(0.7)$ & $2(0.7)$ & $65(22.9)$ & $284(17.1)$ & \multirow{3}{*}{$<0.01$} \\
\hline No & $696(50.9)$ & $298(21.8)$ & $286(20.9)$ & $3(0.2)$ & $9(0.7)$ & $382(28.0)$ & $1367(82.4)$ & \\
\hline Missing & $5(71.4)$ & $1(14.3)$ & $1(14 \cdot 3)$ & $\mathrm{o}(0)$ & $0(0)$ & $1(14.3)$ & $7(0.4)$ & \\
\hline \multicolumn{9}{|c|}{ Interval between symptom onset and swab } \\
\hline $0-1$ days & $386(57.6)$ & $132(19.7)$ & $124(18.5)$ & $\mathrm{o}(0)$ & $8(1.2)$ & $160(23.9)$ & $670(40.4)$ & \multirow{3}{*}{$<0.01$} \\
\hline $2-4$ days & $421(48.9)$ & $188(21.9)$ & $182(21.2)$ & $3(0.3)$ & $3(0.3)$ & $254(29.5)$ & $860(51.9)$ & \\
\hline 5-7 days & $66(51.6)$ & $28(21.9)$ & $26(20.3)$ & $2(1.6)$ & o (o) & $34(26.6)$ & $128(7.7)$ & \\
\hline \multicolumn{9}{|l|}{ Vaccination status $^{e}$} \\
\hline Unvaccinated & $742(52.4)$ & $308(21.7)$ & $294(20.8)$ & $3(0.2)$ & $11(0.8)$ & $377(26.6)$ & $1416(85.4)$ & \multirow{2}{*}{0.62} \\
\hline Vaccinated (TIV) & $131(54.1)$ & $40(16.5)$ & $38(15.7)$ & $2(0.8)$ & $\mathrm{o}(\mathrm{o})$ & $71(29.3)$ & $242(14.6)$ & \\
\hline
\end{tabular}

TIV: trivalent inactivated vaccine.

a The 11 samples positive for influenza $A\left(\mathrm{H}_{1} \mathrm{~N}_{1}\right)$ pdmog and influenza $B$ are included in both the count of «Total $A$ `column and the «B〉 column.

b Percentage based on total of each row.

Percentage based on the total of 1,658 .

${ }^{\mathrm{d}}$ Analysis performed for influenza positive (cases) vs negative (controls).

e Individuals receiving quadrivalent inactivated influenza vaccine (QIV) $(n=12)$ were excluded from the table and analysis.

percentage. VE was estimated for influenza $A$ and $B$ together and for the specific influenza subtypes, for each of the two seasons. VE was not calculated for certain influenza types and subtypes if the total number of positive samples for the type or subtype was very low, not allowing at least 5 samples in each cell of the contingency table used for OR calculation. Individuals were considered vaccinated if they received the influenza vaccine 14 days or more before disease onset. For children between the ages of 6 months and 9 years receiving the influenza vaccine for the first time, only those receiving two doses, with the second dose given 14 days or more before illness, were included in the analysis. Individuals whose samples were taken more than 7 days after of onset of symptoms were excluded from analysis. Because relatively few individuals received LAIV or QIV during the two influenza seasons, we estimated VE for TIV only.

\section{Statistical analysis}

Percentages were compared using the Mantel-Haenszel chi-squared test. OR for crude VE calculation was performed using a univariate logistic regression model with no covariates. We adjusted for age group, sex, calendar week of sample collection, days from disease onset to swab and underlying chronic medical conditions (information regarding chronic conditions was available for the $2015 / 16$ season only) using multivariable logistic regression. Sensitivity analysis was carried out to evaluate whether there was a difference between individuals who were swabbed on days 0-1 from symptom onset and individuals who were swabbed on days 2-7 from symptom onset. Statistical analyses were carried out using SAS version 9.4 (SAS Institute, Cary, NC, US).

\section{Ethical consideration}

Sentinel influenza surveillance in Israel, including the testing component, is conducted in accordance with the Public Health Ordinance enacted in Israel and does not require informed consent. Molecular characterisation of influenza strains isolated from patients was approved by the ethics committee at the Sheba Medical Center (1967-15-SMC), Tel Hashomer, Israel. 
Vaccine effectiveness estimates for trivalent inactivated vaccine based on influenza-positive and influenza-negative samples among cases and controls, Israel, influenza season 2014/15 $(\mathrm{n}=1,005)$

\begin{tabular}{|c|c|c|c|c|c|c|c|}
\hline \multirow[t]{2}{*}{$\begin{array}{l}\text { Influenza } \\
\text { type/subtype }\end{array}$} & \multirow[t]{2}{*}{ Age } & \multicolumn{2}{|c|}{$\begin{array}{l}\text { Cases } \\
(\mathrm{n}=307)\end{array}$} & \multicolumn{2}{|c|}{$\begin{array}{l}\text { Controls } \\
(n=698)\end{array}$} & \multirow{2}{*}{$\begin{array}{l}\text { Crude VE } \\
\%(95 \% \mathrm{Cl})\end{array}$} & \multirow{2}{*}{$\begin{array}{l}\text { Adjusted VE } \\
\%(95 \% \mathrm{Cl})\end{array}$} \\
\hline & & Vaccinated & Unvaccinated & Vaccinated & Unvaccinated & & \\
\hline \multirow{3}{*}{$A$ and $B$} & All & 59 & 248 & 121 & 577 & $-13.4(-60.2$ to 19.7$)$ & $-4.8(-54.8 \text { to } 29.0)^{a}$ \\
\hline & 6 months -17 years & 24 & 151 & 68 & 345 & $19.4(-33.4$ to 51.2$)$ & $30.5(-18.3 \text { to } 59.1)^{\mathrm{b}}$ \\
\hline & $\geq 18$ years & 35 & 97 & 53 & 232 & $-58.0(-157.4$ to 3.1$)$ & $-53.7(-166.8 \text { to } 11.4)^{b}$ \\
\hline \multirow{3}{*}{$\mathrm{A}\left(\mathrm{H}_{3} \mathrm{~N}_{2}\right)$} & All & 53 & 204 & 121 & 577 & $-23.9(-77.6$ to 13.6$)$ & $-15.8(-72.8 \text { to } 22.4)^{a}$ \\
\hline & 6 months -17 years & 24 & 133 & 68 & 345 & $8.4(-51.9$ to 44.8$)$ & $22.7(-31.7 \text { to } 54.6)^{b}$ \\
\hline & $\geq 18$ years & 29 & 71 & 53 & 232 & $-78.8(-202.3$ to -5.8$)$ & $-75.7(-216.3 \text { to } 2.4)^{b}$ \\
\hline
\end{tabular}

VE: vaccine effectiveness.

adjusted for age group, sex, calendar week and time (days) from symptom onset to swab.

${ }^{b}$ Adjusted for sex, calendar week and time (days) from symptom onset to swab.

\section{Results}

\section{Influenza season and virus circulation}

2014/15 influenza season

During the 2014/15 influenza surveillance season, 1,142 samples were collected from ILI patients. A total of $327(28.6 \%)$ samples were positive for influenza, of which 297 (90.8\%) samples were positive for influenza $A$, and $30(9.2 \%)$ were positive for influenza B. Of the 297 influenza A samples, 274 (92.3\%) were $A\left(\mathrm{H}_{3} \mathrm{~N}_{2}\right), 19$ (6.4\%) were $A\left(\mathrm{H}_{1} \mathrm{~N}_{1}\right)$ pdmog, and 4 (1.3\%) were un-subtyped (Figure $1 \mathrm{~A}$ ) [20]. Characterisation of 22 influenza B samples demonstrated that 21 samples belonged to the Yamagata lineage and 1 belonged to the Victoria lineage.

Molecular characterisation of a convenience sample of 22 influenza $A\left(\mathrm{H}_{3} \mathrm{~N}_{2}\right)$ viruses from community sentinel patients, showed that all belonged to the $3 \mathrm{C} .2 \mathrm{a}$ clade, while the vaccine strain influenza $\mathrm{A} /$ Texas/50/2012 $\left(\mathrm{H}_{3} \mathrm{~N}_{2}\right)$ belonged to the $3 \mathrm{C} .1$ clade. A detailed description and phylogenetic tree were previously reported [21].

\section{5/16 influenza season}

Of the 1,919 samples that were collected from ILI patients during the $2015 / 16$ influenza season, a total of $853(44.5 \%)$ samples were positive for influenza, of which $377(44.2 \%)$ samples were positive for influenza $A$, and $487(57.1 \%)$ were positive for influenza $B$. Of the 377 influenza A samples, 371 (98.4\%) were $A\left(\mathrm{H}_{1} \mathrm{~N}_{1}\right)$ pdmo9, and 6 (1.6\%) were $A\left(\mathrm{H}_{3} \mathrm{~N}_{2}\right)$ (Figure $1 \mathrm{~B}$ ) [4]. $A$ total of 11 samples (1.3\% of the positive influenza samples) were positive for both influenza $A\left(\mathrm{H}_{1} \mathrm{~N}_{1}\right)$ pdmog and influenza B [22].

Molecular characterisation of a convenience sample of 31 influenza $A\left(\mathrm{H}_{1} \mathrm{~N}_{1}\right)$ pdmog viruses from community sentinel patients, showed that 16 belonged to the
6B.1 clade and 15 to the 6B.2 clade, while the vaccine strain $A / C a l i f o r n i a / 07 / 2009\left(\mathrm{H}_{1} \mathrm{~N}_{1}\right)$ pdmog belonged to clade 1. Molecular characterisation of 452 Influenza B viruses demonstrated that $394(87.2 \%)$ belonged to the Victoria lineage, and 58 (12.8\%) belonged to the Yamagata lineage, while the $B$ components of the trivalent vaccine, $\mathrm{B} /$ Phuket/3073/2013, belonged to the Yamagata lineage [22].

\section{Study population}

\section{4/15 influenza season}

Of the 1,142 samples collected from patients with ILI, 127 samples were excluded due to missing vaccination status or vaccination dates, missing day of symptom onset, sampling more than 7 days after onset of symptoms, receipt of influenza vaccine less than 14 days before disease onset, or because of partial vaccination (children less than 9 years old require two vaccine doses) (Figure 2). Of the 1,015 remaining ILI patients (316 cases and 699 controls), 10 received the LAIV (Figure 2); all 10 were less than 13.5 years of age and excluded from the study. The remaining vaccinated patients received the trivalent injected egg-grown vaccine (split or inactivated) containing an $\mathrm{A} /$ California/7/2009 $\left(\mathrm{H}_{1} \mathrm{~N}_{1}\right)$ pdmo9-like virus, an A/Texas/50/2012( $\left.\mathrm{H}_{3} \mathrm{~N}_{2}\right)$-like virus and a B/Massachusetts/2/2012-like virus. The characteristics of the 1,005 samples that were included in the assessment are presented in Table 1.

\section{5/16 influenza season}

Of the 1,919 samples collected from ILI patients, a total of 249 samples were excluded due to missing vaccination status or vaccination dates, missing day of symptoms onset, sampling more than 7 days after onset of symptoms, receipt of influenza vaccine less than 14 days before disease onset, partial vaccination (children less than 9 years old require two vaccine doses) and missing vaccine type (Figure 2 ). Of the 1,670 remaining ILI patients (788 cases and 882 controls), 12 received 
Vaccine effectiveness estimates for trivalent inactivated vaccine based on influenza-positive and influenza-negative samples among cases and controls, Israel, influenza season 2015/16 $(n=1,658)$

\begin{tabular}{|c|c|c|c|c|c|c|c|}
\hline \multirow[t]{2}{*}{$\begin{array}{l}\text { Influenza } \\
\text { type/subtype }\end{array}$} & \multirow[t]{2}{*}{ Age } & \multicolumn{2}{|c|}{$\begin{array}{l}\text { Cases } \\
(n=785)\end{array}$} & \multicolumn{2}{|c|}{$\begin{array}{l}\text { Controls } \\
(n=873)\end{array}$} & \multirow{2}{*}{$\begin{array}{l}\text { Crude VE } \\
\%(95 \% \mathrm{Cl})\end{array}$} & \multirow{2}{*}{$\begin{array}{l}\text { Adjusted VE } \\
\%(95 \% \mathrm{Cl})\end{array}$} \\
\hline & & Vaccinated & Unvaccinated & Vaccinated & Unvaccinated & & \\
\hline \multirow{3}{*}{$A$ and $B$} & All & 111 & 674 & 131 & 742 & $6.7(-22.6$ to 29.0$)$ & $8.8(-25.1 \text { to } 33.5)^{a}$ \\
\hline & 6 months -17 years & 55 & 310 & 44 & 406 & $-63.7(-149.9$ to -7.2$)$ & $-25.0(-98.0 \text { to } 21.0)^{b}$ \\
\hline & $\geq 18$ years & 56 & 364 & 87 & 336 & $40.6(14.2$ to 58.8$)$ & $39.1(7.8 \text { to } 59.8)^{b}$ \\
\hline \multirow{3}{*}{$\begin{array}{l}\mathrm{A}\left(\mathrm{H}_{1} \mathrm{~N}_{1}\right) \\
\mathrm{pdmog}^{c}\end{array}$} & All & 38 & 305 & 131 & 742 & $29.4(-3.7$ to 52.0$)$ & $32.3(-4.3 \text { to } 56.1)^{\mathrm{a}}$ \\
\hline & 6 months -17 years & 17 & 112 & 44 & 406 & $-40.1(-154.6$ to 22.9$)$ & $-8.1(-104 \text { to } 42.7)^{b}$ \\
\hline & $\geq 18$ years & 21 & 193 & 87 & 336 & $58.0(30.1$ to 74.7$)$ & $56.5(24.3 \text { to } 75.0)^{b}$ \\
\hline \multirow{3}{*}{$\mathrm{B}^{\mathrm{c}}$} & All & 71 & 377 & 131 & 742 & $-6.7(-46.1$ to 22.1$)$ & $-2.2(-47.0 \text { to } 29.0)^{a}$ \\
\hline & 6 months -17 years & 38 & 204 & 44 & 406 & $-71.9(-173.8$ to -7.9$)$ & $\begin{array}{c}-25.0(-106.8 \text { to } \\
24.5)^{\mathrm{b}}\end{array}$ \\
\hline & $\geq 18$ years & 33 & 173 & 87 & 336 & $26.3(-14.5$ to 52.6$)$ & $26.5(-20.6 \text { to } 55.2)^{b}$ \\
\hline
\end{tabular}

${ }^{a}$ Adjusted for age group, sex, calendar week, underlying condition and time (days) from symptom onset to swab.

${ }^{\mathrm{b}}$ Adjusted for sex, calendar week, underlying condition and time (days) from symptom onset to swab.

c The 11 samples positive for influenza $A\left(\mathrm{H}_{1} \mathrm{~N}_{1}\right)$ pdmog and influenza $B$ in the 2015/16 season are included in the analysis of influenza $A\left(\mathrm{H}_{1} \mathrm{~N}_{1}\right)$ pdmog and influenza B.

the injectable quadrivalent egg-grown split virus vaccine (QIV) and were excluded from the study. No LAIV was available in Israel during the $2015 / 16$ influenza season. The 242 vaccinated individuals received the trivalent injected egg-grown vaccine (split or inactivated) containing an $\mathrm{A} /$ California/7/2009( $\left.\mathrm{H}_{1} \mathrm{~N}_{1}\right)$ pdmog-like virus, an $\mathrm{A} / \mathrm{Switzerland} / 9715293 / 2013\left(\mathrm{H}_{3} \mathrm{~N} 2\right)$-like virus and a B/Phuket/3073/2013-like virus. The characteristics of the 1,658 samples eligible for VE analysis are detailed in Table 2.

\section{Vaccine effectiveness estimates against influenza virus}

\section{4/15 influenza season}

For the 2014/15 season, adjusted TIV VE against influenza $A$ and $B$ adjusted for age group, gender and calendar week was $-4.8 \%$ (95\% Cl: -54.8 to 29.0 ) (Table 3 ). The adjusted VE against the 2014/15 influenza $A\left(\mathrm{H}_{3} \mathrm{~N}_{2}\right)$ was $-15.8 \%$ (95\% Cl: -72.8 to 22.4 ) (Table 3 ). We did not calculate VE for influenza $A\left(\mathrm{H}_{1} \mathrm{~N}_{1}\right)$ pdmog or influenza $B$ in the $2014 / 15$ season due to the small number of positive samples (17 and 30 samples, respectively).

\section{5/16 influenza season}

The adjusted TIV VE against influenza $A$ and $B$ viruses for $2015 / 16$ season for all ages was $8.8 \%(95 \% \mathrm{Cl}$ : -25.1 to 33.5 ) (Table 4 ). The adjusted TIV VE against the 2015/16 influenza $A\left(\mathrm{H}_{1} \mathrm{~N}_{1}\right)$ pdmog was $32.3 \%$ (95\% Cl: -4.3 to 56.1), and the adjusted VE against the $2015 / 16$ influenza B was $-2.2 \%$ (95\% Cl: -47.0 to 29.0 ) (Table 4). Since only five individuals were infected with influenza $A\left(\mathrm{H}_{3} \mathrm{~N}_{2}\right)$, no $V E$ analysis was performed for this subtype.

\section{Sensitivity analysis}

Sensitivity analysis demonstrated substantial differences in VE estimates between individuals who were swabbed on days 0-1 days vs 2-7 days from disease onset in the $2014 / 15$ and the $2015 / 16$ seasons (Table 5).

\section{Vaccine effectiveness estimates stratified by age}

\section{4/15 influenza season}

For the 2014/15 season, the adjusted TIV VE for influenza $A$ and $B$ were $30.5 \%$ (95\% Cl: -18.3 to 59.1 ) for individuals less than 18 years of age, and $-53.7 \%$ (95\% $\mathrm{Cl}:-166.8$ to 11.4 ) for adults 18 years of age and over. The adjusted TIV VE against influenza $\mathrm{A}\left(\mathrm{H}_{3} \mathrm{~N}_{2}\right)$ alone was $22.7 \%$ (95\% Cl: -31.7 to 54.6$)$ for individuals less than 18 years of age, and $-75.7 \%(95 \% \mathrm{Cl}:-216.3$ to 2.4) for adults 18 years and over (Table 3 ).

\section{5/16 influenza season}

For the 2015/16 season, the adjusted TIV VE for individuals 18 years of age and over was $39.1 \%(95 \% \mathrm{Cl}$ : 7.8 to 59.8 ) against any influenza, $56.5 \%$ (95\% Cl: 24.3 to 75.0$)$ against influenza $\mathrm{A}\left(\mathrm{H}_{1} \mathrm{~N}_{1}\right) \mathrm{pdmog}$, and $26.5 \%$ ( $95 \% \mathrm{Cl}$ : -20.6 to 55.2 ) against influenza B (Table 4 ).

For individuals less than 18 years of age, the adjusted TIV VE was $-25.0 \%$ (95\% Cl: -98.0 to 21.0$)$, against any influenza, $-8.1 \%(95 \% \mathrm{Cl}:-104$ to 42.7$)$ against $\mathrm{A}\left(\mathrm{H}_{1} \mathrm{~N}_{1}\right)$ pdmo9, and $-25.0 \%(95 \% \mathrm{Cl}:-106.8$ to 24.5$)$ against influenza B (Table 4 ). 
Sensitivity analysis of trivalent inactivated influenza vaccine effectiveness in preventing medically attended laboratory confirmed influenza, Israel, influenza seasons 2014/15 and 2015/16 ( $\mathrm{n}=1,005$ and 1,658, respectively)

\begin{tabular}{|c|c|c|c|c|c|c|c|c|}
\hline \multirow{2}{*}{$\begin{array}{l}\text { Influenza } \\
\text { Season }\end{array}$} & \multirow{2}{*}{$\begin{array}{l}\text { Influenza } \\
\text { type/ } \\
\text { subtype }\end{array}$} & \multirow{2}{*}{$\begin{array}{l}\text { Time of sample } \\
\text { collection }\end{array}$} & \multicolumn{2}{|c|}{ Cases } & \multicolumn{2}{|c|}{ Controls } & \multirow{2}{*}{$\begin{array}{c}\text { Crude VE } \\
\%(95 \% \mathrm{Cl})\end{array}$} & \multirow{2}{*}{$\begin{array}{l}\text { Adjusted VEa } \\
\%(95 \% \mathrm{Cl})\end{array}$} \\
\hline & & & Vaccinated & Unvaccinated & Vaccinated & Unvaccinated & & \\
\hline \multirow{4}{*}{$2014 / 15$} & \multirow{2}{*}{$A+B$} & $\begin{array}{l}\text { <2 days after } \\
\text { disease onset }\end{array}$ & 34 & 115 & 59 & 306 & $-53.3(-146.2$ to $4 \cdot 5)$ & $-41.8(-144.5$ to 17.7$)$ \\
\hline & & $\begin{array}{l}\text { 2-7 days after } \\
\text { disease onset }\end{array}$ & 25 & 133 & 62 & 271 & $17.8(-36.6$ to 50.6$)$ & $20.9(-39.8$ to 55.2$)$ \\
\hline & \multirow{2}{*}{$\mathrm{A}\left(\mathrm{H}_{3} \mathrm{~N}_{2}\right)$} & $\begin{array}{l}\text { <2 days after } \\
\text { disease onset }\end{array}$ & 31 & 95 & 59 & 306 & $\begin{array}{c}-69.3(-176.9 \text { to } \\
-3.5)\end{array}$ & $-61.9(-183.0$ to 7.4$)$ \\
\hline & & $\begin{array}{l}\text { 2-7 days after } \\
\text { disease onset }\end{array}$ & 22 & 109 & 62 & 271 & $11.8(-50.6$ to 48.3$)$ & $14.7(-153.7$ to 52.7$)$ \\
\hline \multirow{6}{*}{$2015 / 16$} & \multirow{2}{*}{$A+B$} & $\begin{array}{l}\text { <2 days after } \\
\text { disease onset }\end{array}$ & 32 & 252 & 52 & 334 & $18.4(-30.5$ to 49.0$)$ & $22.8(-29.1$ to 53.9$)$ \\
\hline & & $\begin{array}{l}2-7 \text { days after } \\
\text { disease onset }\end{array}$ & 79 & 422 & 79 & 408 & $3.3(-35.9$ to 31.2$)$ & $1.1(-49.3$ to 34.5$)$ \\
\hline & \multirow{2}{*}{$\begin{array}{l}\mathrm{A}\left(\mathrm{H}_{1} \mathrm{~N}_{1}\right) \\
\mathrm{pdmog}^{\mathrm{b}}\end{array}$} & $\begin{array}{l}\text { <2 days after } \\
\text { disease onset }\end{array}$ & 14 & 118 & 52 & 334 & $23.8(-42.6$ to 59.3$)$ & $-47.8(-192.4$ to 25.3$)$ \\
\hline & & $\begin{array}{l}\text { 2-7 days after } \\
\text { disease onset }\end{array}$ & 24 & 187 & 79 & 408 & $33.7(-8.1$ to 59.3$)$ & $-41.0(-147.4$ to 19.6$)$ \\
\hline & \multirow{2}{*}{$\mathrm{B}^{\mathrm{b}}$} & $\begin{array}{l}<2 \text { days after } \\
\text { disease onset }\end{array}$ & 18 & 142 & 52 & 334 & $18.6(-44.1$ to 54.0$)$ & $26.7(-37.1$ to 60.8$)$ \\
\hline & & $\begin{array}{l}2-7 \text { days after } \\
\text { disease onset }\end{array}$ & 53 & 235 & 79 & 408 & $-16.5(-70.9$ to 20.6$)$ & $-18.5(-88.8$ to 25.6$)$ \\
\hline
\end{tabular}

a Adjusted for age group, sex and calendar week for 2014/15, and adjusted for age group, sex, calendar week and underlying condition for 2015/16.

b The 11 samples positive for influenza $A\left(\mathrm{H}_{1} \mathrm{~N}_{1}\right)$ pdmog and influenza $B$ in the $2015 / 16$ season are included in the analysis of influenza $A\left(\mathrm{H}_{1} \mathrm{~N}_{1}\right)$ pdmog and influenza B.

\section{Discussion}

This was the first study in Israel to evaluate influenza VE in the community using the test-negative case-control design. In this study we evaluated two seasons with different circulation of influenza viruses. We found that in the 2014/15 season, which was characterised by the predominance of a drifted strain of influenza $\mathrm{A}\left(\mathrm{H}_{3} \mathrm{~N}_{2}\right)$, the TIV was not effective. These findings are consistent with reported VE against community influenza $A\left(\mathrm{H}_{3} \mathrm{~N}_{2}\right)$ from the UK $[18,23]$, Canada [24], the US [25-27], Navarra, Spain [28] and Austria [29] in the same season.

These results are also consistent with the findings of an Israeli study demonstrating that sera from Israeli individuals vaccinated with the $2014 / 15$ injected split virus vaccine had reduced ability to neutralise the drifted influenza $\mathrm{A}\left(\mathrm{H}_{3} \mathrm{~N}_{2}\right)$ virus [21]. Although the 2014/15 influenza vaccine was not effective against outpatient influenza $\mathrm{A}\left(\mathrm{H}_{3} \mathrm{~N}_{2}\right)$ in our study, several studies demonstrated a better VE against preventing influenza $\mathrm{A}\left(\mathrm{H}_{3} \mathrm{~N}_{2}\right)$-associated hospitalisations $[30,31]$, reaching $43 \%$ in one study [30].

For the 2015/16 influenza season, which was characterised by the co-dominance of influenza $A\left(\mathrm{H}_{1} \mathrm{~N}_{1}\right)$ pdmog and influenza $B$, VE estimates varied by virus and age group. The TIV was moderately effective against influenza $A\left(\mathrm{H}_{1} \mathrm{~N}_{1}\right)$ pdmog in adults over the age of 18 but not in those 6 months to 17 years of age. Low (and not statistically significant) TIV VE was demonstrated against influenza B in either age group.

Our TIV VE results against influenza $A\left(\mathrm{H}_{1} \mathrm{~N}_{1}\right)$ pdmog in adults during the $2015 / 16$ season are consistent with VE results of the inactivated vaccine against laboratory confirmed influenza $A\left(\mathrm{H}_{1} \mathrm{~N}_{1}\right)$ pdmog in primary care setting in the US [32], Canada [33], European countries that are part of the Influenza Monitoring Vaccine Effectiveness in Europe (I-MOVE) [34] and the UK [35]. Likewise, the molecular characterisation results for influenza $A\left(\mathrm{H}_{1} \mathrm{~N}_{1}\right)$ pdmog in Israel are consistent with other northern hemisphere results, showing that they belong to clades 6B.1 and 6B.2 [33,35,36].

Although most influenza B viruses detected in Israel during the $2015 / 16$ season belonged to the Victoria lineage, the 2015/16 TIV contained only the Yamagata lineage. In contrast to the 2015/2016 influenza season, during the 2012/13 and 2013/14 influenza seasons, the Yamagata lineage predominated in Israel [37]. Little influenza B, mostly of the Yamagata lineage, circulated in Israel during the 2014/15 season. Thus, our low TIV $V E$ results against influenza $B$ may stem from a lineage mismatch between the dominant influenza $B$ virus and the 2015/16 TIV influenza B component, along with reduced exposure to the Victoria lineage in the previous three seasons. 
The low VE against influenza B in 2015/2016 in Israel differed from VE estimates from the US of $58 \%$ ( $95 \%$ $\mathrm{Cl}: 40$ to 70$)$ against the Victoria lineage and 59\% (95\% $\mathrm{Cl}: 45$ to 69 ) against the Yamagata Lineage [32,38]. It also differed from VE estimate of around $50 \%$ among individuals less than 65 years of age in the UK, where, like in Israel, the Victoria lineage influenza B predominated [35]. Although, the VE of $76.5 \%(95 \% \mathrm{Cl}: 41.9$ to 90.5) for those 2 to 17 years of age in the UK can be attributed, at least in part, to the use of LAIV, the VE results of individuals between the ages of 18 and 64 in the UK who mostly received the TIV [35], suggest a different mechanism of protection.

The difference in VE results against influenza $A\left(\mathrm{H}_{1} \mathrm{~N}_{1}\right)$ pdmog between the two age groups examined in our study is interesting. The vaccine was moderately effective in adults, a finding consistent with studies from the UK and US $[32,35]$. However, the low VE against influenza $A\left(\mathrm{H}_{1} \mathrm{~N}_{1}\right)$ pdmog in those less than 18 years of age in Israel differed from VE estimates in the same age group in those same countries $[32,35]$. Of particular note is the difference from the US study, which showed good VE among children receiving the injectable form of the influenza vaccine (while low VE estimates were found among children receiving the LAIV) [32]. It is worth noting the different vaccination rates among the adult and child controls in our study in 2015/16. While the vaccination rate among adult controls was $20.6 \%$, it was $9.7 \%$ among control children (Table 4 ). By comparison, in the 2014/15 season the vaccination rates were similar in adult and children controls (18.6\% and $16.5 \%$, respectively) (Table 3 ). The low rate of vaccinated controls in those less than 18 years of age may have resulted in reduced precision in VE determination. Our study has several limitations. Our sample size was initially relatively small. However, we were able to add additional sentinel clinics for the $2015 / 16$ season and increase the sample size by ca $40 \%$. In addition, in both seasons we had a small number of participants in certain age groups. For this reason, we estimated VE for age strata of 18 years of age and over andless than 18 years of age. Further increasing our sample size in the future will allow stratification into additional age groups, particularly for seasons in which several influenza types and subtypes co-circulate. For the 2014/15 season we did not collect data regarding chronic medical conditions. However, this information was obtained during the $2015 / 16$ season.

We used convenience sampling to select patients presenting with $\mathrm{ILI}$, similar to other studies in the field $[3,18]$, which may have biased our sample. However, our sentinel clinics represented all seven districts in the country, and therefore, the sample likely represented larger Israeli society with respect to geography and population groups.

To evaluate whether our VE estimates might be influenced by the time elapsed from disease onset to swabbing, we conducted a sensitivity analysis. Our analysis demonstrated substantial differences in VE between patients with samples obtained 0-1 days after disease onset compared with patients with samples collected 2-7 days after disease onset. To account for these differences, we adjusted for days from disease onset to swab in our VE estimation.

We did not have information regarding influenza vaccination in previous years among ILI patients. Thus, we were unable to measure VE considering previous vaccination status. Influenza vaccination in preceding years may affect vaccine effectiveness results. Previous influenza vaccination has been associated with a negative effect on VE in several studies [24,28,39].

In conclusion, using data from a community-based influenza surveillance system in Israel, we estimated VE of inactivated influenza vaccine in the Israeli population for the first time. Our study suggests that VE may vary by season, by influenza type and subtype as well as by age. Our results, and those of others, support the need for continued efforts of estimating influenza VE, both in outpatient and inpatient settings. These efforts are necessary in order to better understand the factors that affect influenza VE and to optimise vaccine composition and use. Timely VE estimates are of paramount importance for the yearly decision regarding influenza vaccine composition.

Members of the Israel Influenza Surveillance Network (IISN)

Arkady Akkerman, Yoav Alkan, Shlomo Amsel, Galab Asala, Shmulik Bulvik, Lev Dynkin, Foad El-Sana, Maharan Faradian, Akiva Fradkin, Eli Gazala, Abdul Hamid Ghazawi, Michael Ginzburg, Bobi Gross, Ali Haj-Daud, Kamil Hashivon, Yael Hass, Khury Jarir, Ella Kliminski, Yoseph Laks, Tali Levenstein, Alexander Lustman, Nadia Mansour Washahi, Nir Marcus, Oded Mazor, Idit Meshulach, Kenani Nagi, Margarita Neimark, Moshe Peltz, Shiri Pergamentzev-Karpol, Nina Podbrezsky, Karen Rechavi, Eran Segal, Nirit Segal, Yuval Shilman, Eva Schlank, Raphael Singer, Paul Slater, Ran Schweid, Nitza Vadas, Oded Vagner, Ronen Yunes, Susana Zelzer, Ran Siebner.

\section{Acknowledgements}

Many thanks to Marta Valenciano, Alain Moren and Esther Kissling from Epiconcept, Richard Pebody from Public Health England and Mark Thompson from the United States Centers for Disease Control and Prevention for valuable discussions and advice. Our gratitude is extended to the supporting teams of the community sentinel clinics. We further thank Anneke Ifrah for language editing. We acknowledge the authors, originating and submitting laboratories of the sequences from GISAID's EpiFlu Database on which part of this research is based. All submitters of data may be contacted directly via the GISAID website www.gisaid.org.

Conflict of interest

None declared. 
Authors' contributions

Study design: HY and AG-F.

Data analysis: HY.

Writing of first draft: HY.

Contribution of epidemiological data: HY, HS, IISN.

Collection of clinical samples: IISN.

Contribution and analysis of virology data: RP, MM, EM.

Statistical analysis: HY, RD, YS.

Data interpretation: AG-F, MK, TS.

Critical revision of manuscript: A G-F, MK, TS.

All co-authors reviewed the manuscript draft and approved the final draft.

\section{References}

1. World Health Organization (WHO). Influenza (Seasonal) - Fact sheet No 211. Geneva: WHO; Jan 2018. [Accessed 28 Jan 2018]. Available from: http://www.who.int/mediacentre/factsheets/ fs211/en/

2. Jimenez-Jorge S, de Mateo S, Delgado-Sanz C, Pozo F, Casas I, Garcia-Cenoz M, et al. Estimating influenza vaccine effectiveness in Spain using sentinel surveillance data. Euro Surveill. 2015;20(28):21187. https://doi.org/10.2807/15607917.ES2015.20.28.21187 PMID: 26212144

3. Radin JM, Hawksworth AW, Myers CA, Ricketts MN, Hansen EA, Brice GT. Influenza vaccine effectiveness: Maintained protection throughout the duration of influenza seasons 2010-2011 through 2013-2014. Vaccine. 2016;34(33):390712. https://doi.org/10.1016/j.vaccine.2016.05.034 PMID: 27265447

4. Israel Center for Disease Control (ICDC). Surveillance of influenza-like illness in Israel. Weekly update report for Week 15, ending 16-Apr-16. Ramat Gan: ICDC; 2016. Available from: http://www.health.gov.il/PublicationsFiles/flu16042016e.pdf

5. Al-Abdallat M, Dawson P, Haddadin AJ, El-Shoubary W, Dueger E, Al-Sanouri T, et al. Influenza hospitalization epidemiology from a severe acute respiratory infection surveillance system in Jordan, January 2008-February 2014. Influenza Other Respi Viruses. 2016;10(2):91-7. https://doi.org/10.1111/irv.12354 PMID: 26505620

6. Refaey S, Amin M, Labib M, Kandeel A. Influenza virus positivity and circulating subtypes among cases of influenzalike illness and severe acute respiratory infection, Egypt, 20122015. East Mediterr Health J. 2016;22(7):527-36. https://doi. org/10.26719/2016.22.7.523 PMID: 27714747

7. Israel Ministry of Health. [Vaccination Guidelines - Influenza]. Jerusalem: Israel Ministry of Health; 2015. Hebrew. Available from: http://www.health.gov.il/UnitsOffice/HD/PH/ epidemiology/td/docs/360_Influenza.pdf

8. Israel Center for Disease Control (ICDC). Summary Report - The 2014/2015 influenza season. Ramat Gan: ICDC; Sep 2015. https://www.health.gov.il/PublicationsFiles/ flu2014-2015_EN.pdf

9. Israel Center for Disease Control (ICDC). Summary Report The 2015/2016 influenza season. Ramat Gan: ICDC; Jul 2016. Available from: www.health.gov.il/PublicationsFiles/flu20152016e.pdf

10. Belongia EA, Simpson MD, King JP, Sundaram ME, Kelley NS, Osterholm MT, et al. Variable influenza vaccine effectiveness by subtype: a systematic review and meta-analysis of testnegative design studies. Lancet Infect Dis. 2016;16(8):94251. https://doi.org/10.1016/S1473-3099(16)00129-8 PMID: 27061888

11. Centers for Disease Control and Prevention (CDC). Influenza Specimen Collection. Atlanta: CDC. [Accessed 17 Oct 2017]. Available from: https://www.cdc.gov/flu/pdf/freeresources/ healthcare/flu-specimen-collection-guide.pdf

12. Bromberg M, Kaufman Z, Mandelboim M, Sefty H, Shalev $\mathrm{V}$, Marom R, et al. [Clinical and virological surveillance of influenza in Israel--implementation during pandemic influenza]. Harefuah. 2009;148(9):577-82, 659. Hebrew. PMID: 20070044

13. Hindiyeh M, Goulding C, Morgan H, Kenyon B, Langer J, Fox L, et al. Evaluation of BioStar FLU OIA assay for rapid detection of influenza $A$ and $B$ viruses in respiratory specimens. J Clin Virol. 2000;17(2):119-26. https://doi.org/10.1016/S13866532(00)00081-0 PMID: 10942092

14. Hindiyeh M, Levy V, Azar R, Varsano N, Regev L, Shalev Y, et al. Evaluation of a multiplex real-time reverse transcriptase PCR assay for detection and differentiation of influenza viruses $A$ and $B$ during the 2001-2002 influenza season in Israel. J Clin Microbiol. 2005;43(2):589-95. https://doi.org/10.1128/ JCM.43.2.589-595.2005 PMID: 15695650

15. Hindiyeh M, Ram D, Mandelboim M, Meningher T, Hirsh S, Robinov J, et al. Rapid detection of influenza A pandemic $\left(\mathrm{H}_{1} \mathrm{~N}_{1}\right) 2009$ virus neuraminidase resistance mutation $\mathrm{H}_{275} \mathrm{Y}$ by real-time reverse transcriptase PCR. J Clin Microbiol. 2010;48(5):1884-7. https://doi.org/10.1128/JCM.02540-09 PMID: 20220153

16. Itoh Y, Shinya K, Kiso M, Watanabe T, Sakoda Y, Hatta M, et al. In vitro and in vivo characterization of new swine-origin $\mathrm{H}_{1} \mathrm{~N}_{1}$ influenza viruses. Nature. 2009;46o(7258):1021-5. https://doi. org/10.1038/natureo8260 PMID: 19672242

17. World Health Organization (WHO). Sequencing primers and protocol. Geneva: WHO; 12 May 2009. [Accessed 26 Jan 2018]. Available from: http://www.who.int/csr/resources/ publications/swineflu/sequencing_primers/en/

18. Pebody R, Warburton F, Andrews N, Ellis J, von Wissmann B, Robertson $C$, et al. Effectiveness of seasonal influenza vaccine in preventing laboratory-confirmed influenza in primary care in the United Kingdom: 2014/15 end of season results. Euro Surveill. 2015;20(36):30013. https://doi.org/10.2807/15607917.ES.2015.20.36.30013 PMID: 26535911

19. Valenciano $M$, Kissling $E$, Reuss $A$, Jiménez-Jorge $S$, Horváth JK, Donnell JM, et al. The European I-MOVE Multicentre 2013-2014 Case-Control Study. Homogeneous moderate influenza vaccine effectiveness against $A\left(\mathrm{H}_{1} \mathrm{~N}_{1}\right)$ pdmog and heterogenous results by country against $A\left(H_{3} \mathrm{~N}_{2}\right)$. Vaccine. 2015;33(24):2813-22. https://doi.org/10.1016/j.vaccine.2015.04.012 PMID: 25936723

20. Israel Center for Disease Control (ICDC). Surveillance of influenza-like illness in Israel. Weekly update report for Week 16, ending 18-Apr-15. Ramat Gan: ICDC; 2015 . Available from: http://www.health.gov.il/PublicationsFiles/flu18042015e.pdf

21. Mandelboim M, Glatman-Freedman A, Drori Y, Sherbany $H$ Pando R, Sefty H, et al. Ineffectiveness of the 2014-2015 $\mathrm{H}_{3} \mathrm{~N}_{2}$ influenza vaccine. Oncotarget. 2016;7(2):1185-92. https://doi. org/10.18632/oncotarget.6746 PMID: 26716420

22. Pando R, Drori Y, Friedman N, Glatman-Freedman A, Sefty $H$, Shohat T, et al. Influenza A(H1N1)pdm 2009 and influenza B virus co-infection in hospitalized and non-hospitalized patients during the 2015-2016 epidemic season in Israel. Journal of Clinical Virology. 2017; Mar 88;12-16. https://doi.org/10.1016/j. jcv.2017.01.002 https://doi.org/ PMID: 28088665

23. Pebody RG, Warburton F, Ellis J, Andrews N, Thompson C, von Wissmann B, et al. Low effectiveness of seasonal influenza vaccine in preventing laboratory-confirmed influenza in primary care in the United Kingdom: 2014/15 mid-season results. Euro Surveill. 2015;20(5):21025. https://doi. org/10.2807/1560-7917.ES2015.20.5.21025 PMID: 25677050

24. Skowronski DM, Chambers C, Sabaiduc S, De Serres G, Winter AL, Dickinson JA, et al. A Perfect Storm: Impact of Genomic Variation and Serial Vaccination on Low Influenza Vaccine Effectiveness During the 2014-2015 Season. Clin Infect Dis. 2016;63(1):21-32. https://doi.org/10.1093/cid/ciw176 PMID: 27025838

25. Flannery B, Clippard J, Zimmerman RK, Nowalk MP, Jackson ML, Jackson LA, et al. Early estimates of seasonal influenza vaccine effectiveness - United States, January 2015. MMWR Morb Mortal Wkly Rep. 2015;64(1):10-5. PMID: 25590680

26. Flannery B, Zimmerman RK, Gubareva LV, Garten RJ, Chung JR, Nowalk MP, et al. Enhanced Genetic Characterization of Influenza $\mathrm{A}\left(\mathrm{H}_{3} \mathrm{~N}_{2}\right)$ Viruses and Vaccine Effectiveness by Genetic Group, 2014-2015. J Infect Dis. 2016;214(7):1010-9. https://doi.org/10.1093/infdis/jiw181 PMID: 27190176

27. Zimmerman RK, Nowalk MP, Chung J, Jackson ML, Jackson LA, Petrie JG, et al. 2014-2015 Influenza Vaccine Effectiveness in the United States by Vaccine Type. Clin Infect Dis. 2016;63(12):1564-73. https://doi.org/10.1093/cid/ciw635 PMID: 27702768

28. Castilla J, Navascués A, Fernández-Alonso M, Reina G, Pozo F, Casado I, et al. Effectiveness of subunit influenza vaccination in the 2014-2015 season and residual effect of split vaccination in previous seasons. Vaccine. 2016;34(11):1350-7. https://doi. org/10.1016/j.vaccine.2016.01.054 PMID: 26854911

29. Redlberger-Fritz M, Kundi M, Popow-Kraupp T. Detailed Report on 2014/15 Influenza Virus Characteristics, and 
Estimates on Influenza Virus Vaccine Effectiveness from Austria's Sentinel Physician Surveillance Network. PLoS One. 2016;11(3):e0149916. https://doi.org/10.1371/journal. pone.0149916 PMID: 26975056

30. Petrie JG, Ohmit SE, Cheng CK, Martin ET, Malosh RE, Lauring AS, et al. Influenza Vaccine Effectiveness Against Antigenically Drifted Influenza Higher Than Expected in Hospitalized Adults: 2014-2015. Clin Infect Dis. 2016;63(8):1017-25. https://doi. org/10.1093/cid/ciw432 PMID: 27369320

31. Puig-Barbera J, Mira-Iglesias A, Tortajada-Girbes M, LopezLabrador FX, Belenguer-Varea A, Carballido-Fernandez M, et al. Effectiveness of influenza vaccination programme in preventing hospital admissions, Valencia, 2014/15 early results. Euro Surveill. 2015;20(8):21044. https://doi. org/10.2807/1560-7917.ES2015.20.8.21044 PMID: 25742432

32. Centers for Disease Control and Prevention (CDC). Influenza vaccine effectiveness, including LAIV vs IIV in children and adolescents, US Flu VE Network, 2015-2016. Atlanta: CDC; 22 Jun 2016. [Accessed 26 Jan 2018]. Available from: http://www. nitag-resource.org/uploads/media/default/0001/03/31080dbc 0778d8efo7c95caeeodd35cb452ada4d.pdf

33. Chambers C, Skowronski DM, Sabaiduc S, Winter AL, Dickinson JA, De Serres G, et al. Interim estimates of 2015/16 vaccine effectiveness against influenza $A\left(\mathrm{H}_{1} \mathrm{~N}_{1}\right)$ pdmog, Canada, February 2016. Euro Surveill. 2016;21(11):30168. https://doi. org/10.2807/1560-7917.ES.2016.21.11.30168 PMID: 27020673

34. Kissling $E$, Valenciano $M$. Early influenza vaccine effectiveness results 2015-16: I-MOVE multicentre case-control study. Euro Surveill. 2016;21(6):30134. https://doi.org/10.2807/1560-7917. ES.2016.21.6.30134 PMID: 26898240

35. Pebody R, Warburton F, Ellis J, Andrews N, Potts A, Cottrell S, et al. Effectiveness of seasonal influenza vaccine for adults and children in preventing laboratory-confirmed influenza in primary care in the United Kingdom: $2015 / 16$ end-of-season results. Euro Surveill. 2016;21(38):30348. https://doi. org/10.2807/1560-7917.ES.2016.21.38.30348 PMID: 27684603

36. European Centre for Disease Prevention and Control (ECDC). Surveillance Report. Influenza characterization report, summary Europe, March 2016. Stockholm: ECDC; 2016. Available from: http://ecdc.europa.eu/en/publications/ Publications/influenza-virus-characterisation-march-2016.pdf

37. Sharabi S, Drori Y, Micheli M, Friedman N, Orzitzer S, Bassal $\mathrm{R}$, et al. Epidemiological and Virological Characterization of Influenza B Virus Infections. PLoS One. 2016;11(8):e0161195. https://doi.org/10.1371/journal.pone.0161195 PMID: 27533045

38. Davlin SL, Blanton L, Kniss K, Mustaquim D, Smith S, Kramer N, et al. Influenza Activity - United States, 2015-16 Season and Composition of the 2016-17 Influenza Vaccine. MMWR Morb Mortal Wkly Rep. 2016;65(22):567-75. https://doi. org/10.15585/mmwr.mm6522a3 PMID: 27281364

39. Saito N, Komori K, Suzuki M, Morimoto K, Kishikawa T, Yasaka $T$, et al. Negative impact of prior influenza vaccination on current influenza vaccination among people infected and not infected in prior season: A test-negative case-control study in Japan. Vaccine. 2017;35(4):687-93. https://doi.org/10.1016/j. vaccine.2016.11.024 PMID: 28043738

\section{License and copyright}

This is an open-access article distributed under the terms of the Creative Commons Attribution (CC BY 4.0) Licence. You may share and adapt the material, but must give appropriate credit to the source, provide a link to the licence, and indicate if changes were made.

This article is copyright of the authors, 2018. 